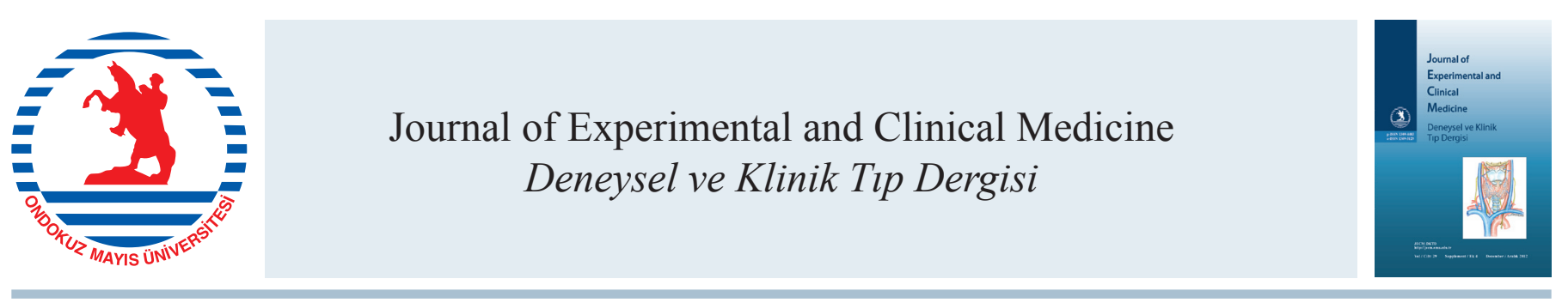

Derleme / Review

doi: $10.5835 /$ jecm.omu.29.s4.015

\title{
Tiroit bezinde radyolojik görüntüleme yöntemleri
}

\author{
Radiologic imaging methods in tyhroid gland
}

\author{
Murat Danaci* \\ Ondokuz Mayıs Üniversitesi, Radyoloji Anabilim Dalı, Tıp Fakültesi, Samsun, Türkiye
}

\begin{tabular}{|c|c|c|}
\hline \multicolumn{2}{|c|}{ MAKALE BİLGÍLERİ } & ÖZET \\
\hline \multicolumn{2}{|c|}{ Makale geçmişi } & Tiroit hastalıklarının tanısında ve takibinde klinik muayene, laboratuar testlerine ilaveten \\
\hline Geliş tarihi & : 07 / 06 / 2012 & radyolojik görüntüleme yöntemleri vazgeçilmez araçlardır. Tiroit görüntülemesinde ilk \\
\hline Kabul tarihi & $: 08 / 08 / 2012$ & $\begin{array}{l}\text { yöntem ultrasonografi olmakla birlikte, doppler ultrasonografi, bilgisayarlı tomografi, } \\
\text { manyetik rezonans görüntüleme ve ince iğne aspirasyon biyopsisi tanıya yardımcı }\end{array}$ \\
\hline \multicolumn{2}{|c|}{ * Yazışma Adresi: } & $\begin{array}{l}\text { diğer yöntemlerdir. Son yıllarda difüzyon manyetik rezonans görüntüleme, perfüzyon } \\
\text { görüntüleme, ultrasound elastografi gibi yeni yöntemler kullanıma girmiștir. Gelinen }\end{array}$ \\
\hline \multicolumn{2}{|c|}{ Murat Danacı } & noktada tiroit görüntülemesinde artan rezolüsyonla birlikte çok daha küçük lezyonlar \\
\hline \multicolumn{2}{|c|}{ Ondokuz Mayıs Üniversitesi, } & saptanabilirken, malign-benign ayrımı tüm bu gelişmelere rağmen halen problemdir. \\
\hline \multicolumn{2}{|c|}{ Tıp Fakültesi } & $\mathrm{Bu}$ çalışmada tiroit hastalıklarının görüntülemesinde kullanılan radyolojik yöntemler, \\
\hline \multicolumn{2}{|c|}{ Radyoloji Anabilim Dalı } & avantajları, sinırlamaları sunulmuştur. \\
\hline \multicolumn{2}{|c|}{ Samsun } & J. Exp. Clln. Med., 2012; 29:\$281 \\
\hline
\end{tabular}

Samsun

e-posta: danacim55@yahoo.com

\section{Anahtar Kelimeler: \\ Tiroit bezi \\ Ultrasonografi \\ Bilgisayarlı tomograf \\ Manyetik rezonans görüntüleme \\ İnce iğne aspirasyon biyopsisi}

\section{Keywords:}

Tyhroid gland

Ultrasonography

Computerized tomography

Magnetic resonance imaging

Fine needle aspiration biopsy

\begin{abstract}
Radiologic imaging methods are ultrasonography is an indispensible technique in the diagnosis and follow-up of thyroid gland in addition to physical examination and laboratory test. Although ultrasonography is a first imaging modality in thyroid gland, doppler sonography, computed tomography, magnetic resonance imaging and fine needle aspiration biopsy are other ancillary techniques for the diagnosis. Recently, new imaging modalities have been used such as magnetic resonance imaging, perfusion imaging and ultrasound elastography. At that time, although more small lesions have been detected by increased resolution, the differences between malign and benign is a problem at present. In this study, we present the radiologic imaging methods using thyroid gland and their advantages and limitations.

J. Exp. Clin. Med., 2012; 29: S281-S288
\end{abstract}

\section{Giriş}

\section{Görüntüleme yöntemleri}

Ultrasonografi (US) tiroit hastalıklarının tanı ve takibinde çok önemli bir yer tutmaktadır. İyonizan 1şın içermeyen, yaygın, ucuz, kolay uygulanan bir yöntemdir. Son yıllarda US teknolojisindeki gelişmeler sayesinde yüksek frekansl1, yüksek rezolüsyonlu problar kullanılmaya başlanmış ve 2-3 mm çaplı nodüller görülür hale gelmiştir. US nodulün büyümesinin takibinde boyutları gösteren objektif bir araçdır. İlaveten renkli Doppler ultrasonografi (RDUS) ile nodüllerin ve diğer tiroit hastalıklarının kanlanma özellikleri değerlendirilebilir (Varverakis ve Neonakis, 2002; Esen, 2006). Tiroit yüzeyel yerleşiminden dolayı yüksek rezolüsyonlu US için uygun bir organdır. İnceleme supin pozisyonda baş hafif ekstansiyonda iken yapılır. Lineer problar kullanılır. İnceleme sirasında sagital ve aksiyal planda tüm tiroit bezi taranır. Tiroit bezi komşu kaslara göre daha hipoekoikdir. Bez boyutları, ekosu değerlendirilir. Tüm fokal lezyonların üç boyutu ve sonografik özellikleri kaydedilir. İnceleme sırasında komşu lenf nodları da değerlendirmeye ilave edilir (Tessler ve Tublin, 1999).

Son 10 yıl içinde yeni görüntüleme yöntemleri ortaya çıkmıştır. Ultrasound elastografi, radyonüklid görüntülemeler, pozitron emisyon tomografi (PET) tanıda kullanılmaya başlanan yeni yöntemlerdir. US elastografi doku elastisitesini gösteren bir yöntemdir. Dıştan uygulanan bası ile dokudaki sertlik düzeyine bakılır. Yumuşak dokular kolayca deforme olurken sert dokular daha az deforme olur. Dokudaki distorsiyon US ile saptanarak doku sertliği değerlendirilir. 
Sert dokular malignite açısından risk taşır (Cochlin ve ark., 2002; Itoh ve ark., 2006). İncelemenin sinırlamaları mevcuttur. Çevresinde normal doku yoksa, kompresyon yapılması güç bir yerde ise yanılgı olabilir. Ayrıca değerlendirme k1smen subjektifdir (Rago ve Vitti, 2008). İncelemenin yararlı olduğunu söyleyen çalışmalar vardır ve ince iğne aspirasyon biyopsisi (İIAB) ile kiyaslanabilecek invaziv olmayan bir yöntem olduğu savunulmaktadır (Lyshchik ve ark., 2005; Rago ve ark., 2007). Elastografi kistik ya da kabuk şeklinde kalsifiye nodüller de yararlı değildir. Yine birbirine yakın konglomerat yapmış nodüller değerlendirmeye uygun değildir. Nodül elastisitesi 1'den 5'e kadar derecelendirilir. Grade 4-5 nodüllerde duyarlılık \% 97, özgüllük \% 100, negatif tahmin değeri \% 98 olarak bildirilen çalışmalar vardır (Rago ve Vitti, 2008). US elastografi tiroit kanseri tanısında potansiyel yeni bir araçtır. Kontrastlı US tiroit nodüllerinin değerlendirilmesinde yeni bir yöntemdir. Yeni US kontrast maddeleri sayesinde benign ve malign nodüllerin kanlanma özellikleri değerlendirilebilmektedir. İlk çalışmalar umut verici olmakla birlikte bu tekniğin rutin kullanıma girmesi için daha fazla çalışmaya ihtiyaç vardır (Albrecht ve ark., 2004).

İIAB halen tiroit nodüllerinin değerlendirilmesinde önemli bir yöntemdir. Yöntem kolay, ucuz ve yararlıdır ancak yetersiz örnekleme ya da nondiagnostik sonuçlar bir problem olarak durmaktadır. Biyopsi yapılacak nodül seçiminde ise hala US değerlendirmesi önemlidir (Layfield ve ark., 2009). Son yıllarda trucut biyopsi yüksek başarı oranıyla kullanılmaya başlanmıştır. Duyarlılık \% 98, özgüllük \% 100 olarak bulunmuştur. İşlemde yan etki ve tümör ekimi bildirilmemiştir. Yöntem lokal anestezi altında US rehberliğinde 18 iğne ile uygulanmaktadır. İşlem İIAB sonucu şüpheli ya da tanısal olmayanlara önerilmektedir (Miltenburg ve ark., 2000; Varverakis ve Neonakis, 2002).

Kesitsel görüntüleme yöntemleri olarak bilgisayarlı tomografi (BT) ve manyetik rezonans görüntüleme (MRG) tiroit nodüllerinin malign-benign ayrımında yararsızdır. Ancak tiroit dışına uzanan ya da komşu organlara infiltre kitle varsa onu gösterebilir. BT'de kullanılan iyotlu kontrast madde tiroit dokusu tarafindan tutulur ve radyoaktif iyot tedavisini geciktirebilir. Subklinik hipertiroidi olgularında sorunlara yol açabilir. Benign tiroit nodüllerinde nodüllerin toraks içine uzanımını saptamada, çevre dokulara basılarını göstermede kullanılmaktadır.

Tiroit kanserlerinde tümör komplike değilse BT ve MRG nin yeri yoktur. Tümör kapsül dışına uzanmış beraberinde nefes darlığı, yutma güçlüğü gibi semptomlar varsa tümör uzanımının değerlendirmesinde kullanılır. Tedavi sonrası dönemde ise tiroglobulin yükselmesi olan olgularda US ya da klinik bulgular yetersiz kalırsa retrofaringeal ya da mediastinal tutulumu değerlendirmede yararlıdır (Cooper ve ark., 2009). Ayrıca pek çok kanser türünde olduğu gibi tiroit kanserlerinin akciğer, karaciğer ya da kemik metastazlarının tanısında kullanılırlar. Bunun dışında baş-boyun bölgesi BT ve MRG görüntülemeleri sırasında tesadüfen tiroit nodülü saptanması sık bir durumdur. Bu konuda yapılan bir çalışmada nodül içi kalsifikasyon kontrastlanma, nodülün ön-arka çapının eninden fazla olması malignite kriteri olarak bildirilmiştir. Nodülde bu bulgularda bir ya da birkaçı saptandığında US kontrolü ve İİAB gerekmektedir (Deandrea ve ark., 2002). MRG son yıllarda yüzeyel koillerin gelişmesi, perfüzyon, difüzyon gibi fonksiyonel MRG yöntemlerinin kullanıma girmesiyle daha önem kazanan bir yöntem olmuştur. Difüzyon su moleküllerinin dokulardaki hareketi üzerinden bilgi sağlayan, invaziv olmayan bir yöntemdir. Perfüzyon görüntülemede yapılan bir çalışmada Graves hastalığında perfüzyonun Haşimoto tiroiditi ve normal dokuya göre arttığını göstermektedir (Schueller-Weidekamm ve ark., 2009). Nodüllerde yapılan difüzyon ağırlıklı görüntülemede apparent diffusion coefficient (ADC) ölçümlerinde malign ve benign nodüller arasında fark bulunmuştur. Malign nodüller de yüksek, benign adenomatöz nodüllerde ise ADC düşük ölçülmüştür (Ophir ve ark., 1991).

\section{Tiroit hastalıkları ve radyolojik bulguları}

Tiroit hastalıkları tüm dünyada yaygın görülür. Doğumsal defektler, travma, Graves hastalığı, Haşimoto tiroiditi, tiroit nodülleri, tiroit kanserleri en sık karşılaşılan hastalıklarıdır. Tiroit hastalıkları difüz ve fokal hastalıklar olarak da ayrılabilir.

\section{Difüz tiroit hastalıkları}

Bezde boyut artışı ile seyrederler ve genel olarak guatr olarak adlandırılır. Bu grupta Graves hastalığı, multinodüler guatr, Haşimoto tiroiditi, enfeksiyöz tiroiditler yer alır (Mulder, 1998).

\section{Graves hastalığı}

Kronik otoimmün bir hastalıktır. US bulguları spesifik değildir. Tanı klinik ve laboratuar bulguları ile konur. US de bez izo ya da hipoekoik ve heterojendir (Vi1 ve ark., 1992). US'de eko paterni bezde azalmış kolloid, artmış selülarite, artmış vaskülarite ve lenfositik infiltrasyon nedeniyle değişir. Doppler US'de difüz artmış kanlanma saptanır ve tiroit inferno olarak adlandırılır (Şek. 1) (Hodgson ve ark., 1988). US'nin diğer bir kullanımı bu olgularda koinsidental gelişen tümör ya da lenfomayı saptamaktır.

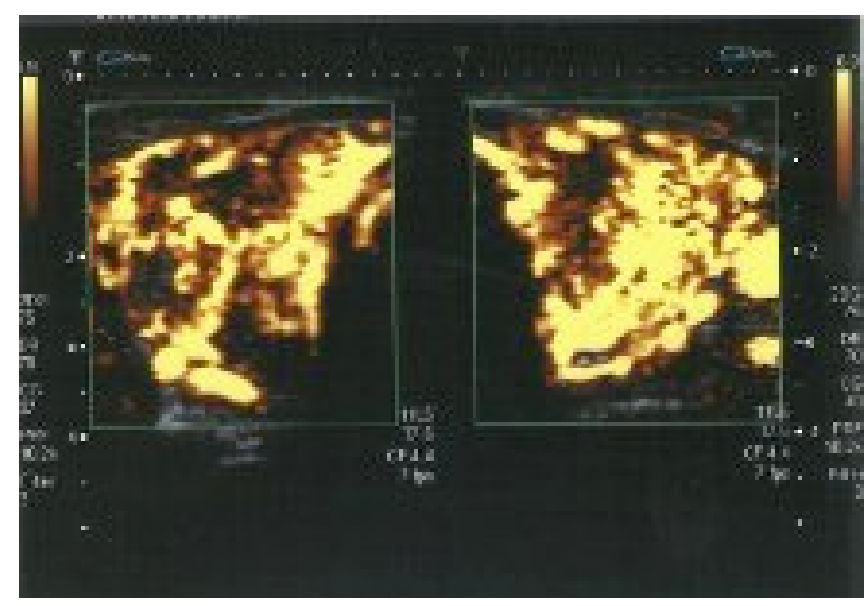

Şek. 1. Graves hastalığı olan olguda, power Doppler ultrasonografide difüz artmış kanlanma ( tiroit inferno)

\section{Haşimoto tiroiditi}

Lenfositik tiroidit olarak da bilinir ve otoimmün tiroiditin bir alt gurubudur. US görünümü değişkendir ve hastalığın şiddetini ve fazını yansıtır. US'de difüz heterojen, hipoekoik ya da mikronodüler patern görülebilir (Şek. 2). Bu haliyle Graves hastalığ1, multinodüler guatr ve subakut tiroiditle karışabilir (Gutekunst ve ark., 1989; Marcocci ve ark., 1991). Olguların bir kısmında nodüler büyüme görülebilir ve has- 


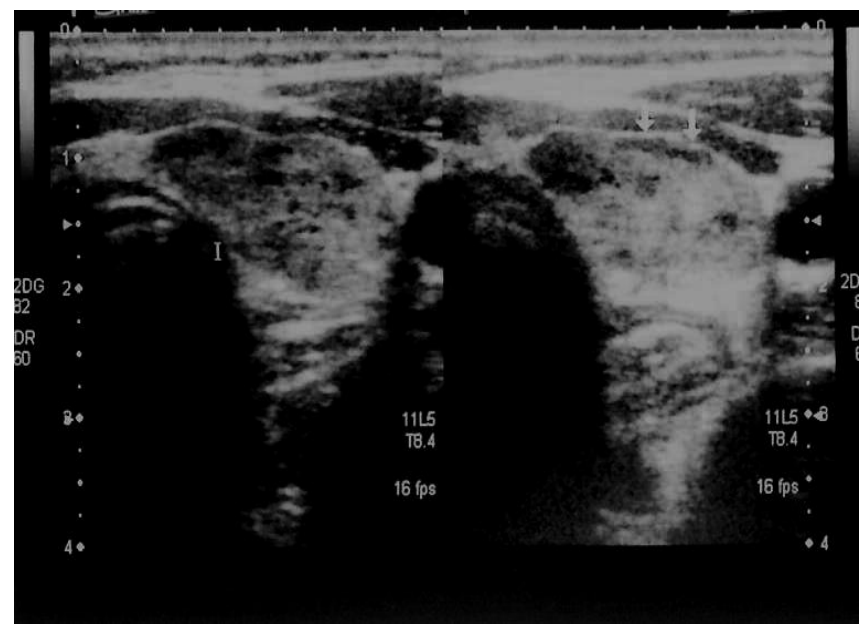

Şek. 2. Haşimoto tiroditi, ultrasonografide bez heterojen, özellikle kapsül altında hipoekoik alanlar

talar biyopsi için refere edilebilir. Nodüllerin Doppler US'de vaskülaritesi değişkendir. Bu lezyonların diğer fokal lezyonlardan ayrımında US bulguları güvenilir olmadığı için biyopsi gerekir (Friedman ve ark., 1981).

\section{Subakut Tiroidit (De Quervan hastalığı)}

Tiroidde granülomatöz enflamasyonla karekterize, kendi kendini sınırlayan bir hastalıkdır. US ile hipoekoik ya da kötü sınırlı nodüller görülebilir (Tessler ve Tublin, 1999).

\section{Akut enfeksiyöz tiroidit}

Spesifik bir US bulgusu yoktur. Klinik bulgularla tanı konur.

\section{Multinodüler guatr}

Bezde boyut artışı ile birlikte çok sayıda ve değişik oranda kolloid, nekroz, hemoraji içeren hiperplastik nodül bulunur. US'de heterojen olabilir, değişik boyut ve görünümde multipl nodüller görülür. Kalsifikasyon kaba ya da rim şeklinde görülebilir. Karakteristik bir Doppler US bulgusu yoktur (Cotran ve ark., 1994).

\section{Fokal tiroit hastalıkları}

Nodüler tiroit hastalıkları tiroidte bir ya da daha fazla palpabl ya da palpabl olmayan nodüllerle karekterize bir durumu tarif eder (Gharib, 1997). Tiroit nodülü çok sık görülmesine rağmen malignite oranı düşüktür. Tiroidin en sık karşılaşılan hastalığı nodülleri olup toplumda görülme sıklığı \% 15-20 siklıktadır. Bu oran US ile yapılan kontrollerde \% 50' ye ulaşmaktadır (Mazzaferri, 1993). Tiroit nodüllerinde malignite oranı \% 5-10 arasındadır (Papini ve ark., 2002). Tiroit nodüllerinin değerlendirilmesinde klinik muayene, US ve İİAB temel yöntemlerdir. Tiroit nodülleri son 50 yılda görüntüleme yöntemlerindeki gelişmelerden dolayı artan sayıda görülmektedir. Yalnız tiroit görüntüleme değil aynı zamanda ince kesitli BT'lerin kullanımı ile insidental nodül saptama oranı da artmıştır (Sameer ve ark., 2010). İnsidental nodüllerin çoğu benign nodül olup, nodüllerde malignite oranı $\% 5^{\prime}$ tir (Desser ve Kamaya, 2008). National Comprehensive Cancer Network (NCCN) 2009'da, 1 cm' den büyük nodüllerin malignite açısından araştırılması önerilmektedir. Bu amaçla boyun US, lenf nodlarının değerlendirilmesi ve İİAB yapılmasının gerekli olduğu bildirilmektedir. Risk faktörleri erkek cinsiyet, 15 yaş altı, 60 yaş üstü olmak, boyuna radyasyon öyküsü, aile öyküsü ve tiroit kanseriyle sık görülen sendromlara sahip olmaktır (ww.nccn.org/professionals/physician_gls/f_ guidelines.). Nodül bir cm'den küçük ve risk faktörü yoksa takip yapılabilir. Multinodüler guatr olgularında malignite riskinin tek nodüle göre daha düşük olduğunu belirten çalışmalar vardır (Sippel ve ark., 2007). Multinodüler olgularda ise kanser $2 / 3$ oranında dominant nodül de görülmektedir (Frates ve ark., 2005). Uygun nodül seçimi için US incelemesi önerilmekte eğer US'de şüpheli nodül yoksa dominant nodülden biyopsi önerilmektedir (Sameer ve ark., 2010). US tiroit nodüllerinin malign-benign ayrımında, şüpheli nodülleri saptama ve biyopsi rehberliğinde yaygın kullanılır. US'de mikrokalsifikasyon, belirgin hipoekojenite, mikrolobüle veya düzensiz kenar, halonun olmaması, intranodüler kanlanma, ön-arka çapın eninden daha uzun oluşu malignite için şüphe uyandıran kriterlerdir (Frates ve ark., 2005; Moon ve ark., 2008). Tiroit nodüllerinde malignite riski açısından tanımlanmış bulgular hızlı büyüyen sert nodül, vokal kord paralizisi, lenf nodu metastazı ve aile öyküsüdür. Tek bir risk faktörü varlığında malignite oranı \% 71 iken iki ya da daha fazlasında oran \% 100' e yaklaşmaktadır (Hamming ve ark., 1990).

\section{Tiroit kanserleri}

ABD' de en sık karşılaşılan endokrin kanserlerdir. Yıllık 35.000 yeni olgu bildirilmekte ancak kanserden ölenlerin say1s1 1500' de kalmaktadır (www.cancer.gov/ ncicancerbulletin). Tiroidde \% 60-80 oranında papiller, \% 15-18 oranında foliküler, $\%$ 3-10 oranında anaplastik, $\%$ 4-5 oranında medüller, \% 5 oranında ise lenfoma ve metastazlar görülmektedir (Hedinger ve ark., 1989).

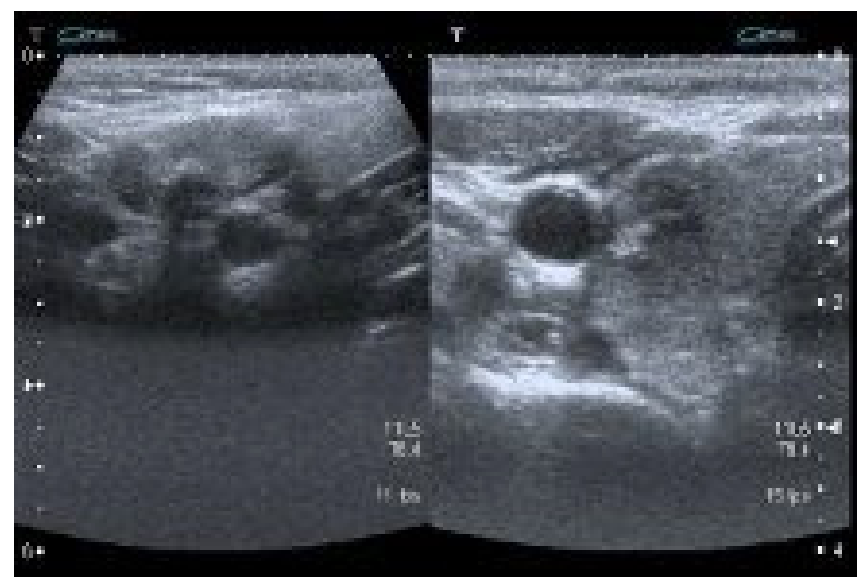

Şek. 3. Papiller kanser, tiroit ultrasonografide parankimde kötü sınırlı mikrokalsifikasyon içeren nodül (sağda), nodülle aynı görünümde mikrokalsifikasyon içeren metastatik lenf adenopati (solda)

Papiller tiroit kanserleri iyi prognoza sahip, uzak metastaz ihtimali daha zayıf ancak servikal lenf nodlarına \% 30-80 arasında metastaz yapan bir grubtur (Şek. 3) (Koike ve ark., 2001). Yüksek rezolüsyonlu US lezyon karekterizasyonu için gerekli detayı sağlar, yine kalsifikasyonları ve nodüler kanlanma özelliklerini gösterir (Şek. 4a,b). Yine US nodülün ve metastaz şüpheli lenf nodunun biyopsisinde rehberlik yapar (Bitterman ve ark., 2006). US lenf nodu metastazlarını saptamada kullanılır ancak retrofaringeal ve mediasten gibi alanlar değerlendirilemez. 


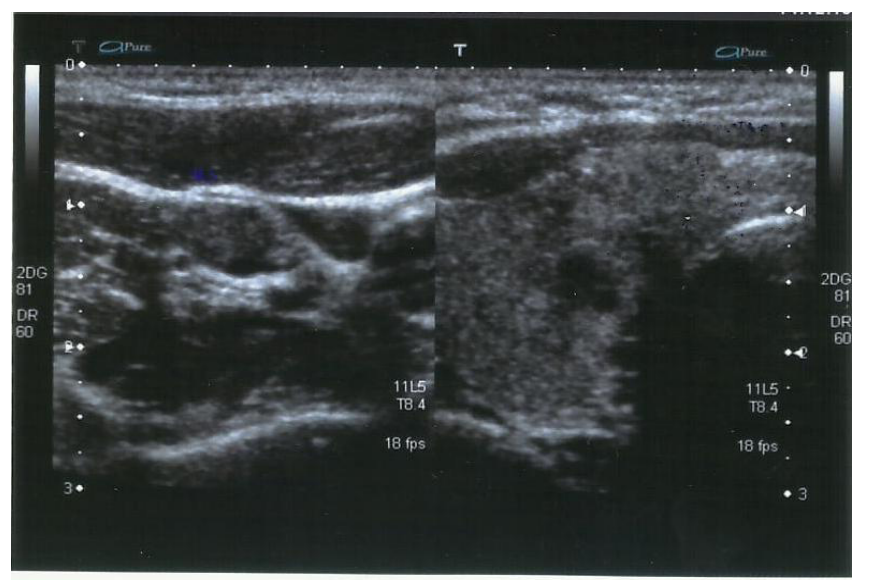

Şek. 4a. Papiller kanserli olguda tiroit bezinde kötü sınırlı mikrokalsifikasyon içeren nodül (sağda), metastatik lenf nodu (solda)

Bu bölgeleri değerlendirmek için BT kullanılır (Shirakawa ve ark., 2001; Ito ve ark., 2004).

Foliküler kanserler foliküler adenomlarla benzerlik gösterirler ancak adenomlar daha sıktır. Adenomda vasküler ve kapsüler invazyon bulgusunun olmaması dışında benzer sitolojik bulgular mevcuttur (Şek. 5). Biyopside foliküler neoplazm tanısı almış olguların \% 80-90'ı adenom, \% 10-20' si karsinom tanısı almaktadır (Stolf ve ark., 2006). İIAB yapılan olgularda \% 29 oranında foliküler lezyon saptanır (Shirakawa ve ark., 2001; Ito ve ark., 2004). Foliküler adenom ve karsinom tanısı sitolojik olarak güç olduğu için çoğu lezyon cerrahi olarak eksize edilir. Ayrımda US güvenilir bir yöntem değildir. US' de riski artıran görünümler artan lezyon volümü, halonun kaybı, hipoekoik görünüm, internal kistik değişiklik olmaması, artmış yaş ve erkek cinsiyettir. US'de foliküler lezyon çevresinde halo adenomda sıktır (Sillery ve ark., 2010). Lezyonun hipoekoik oluşu malignite açısında risk kabul edilir (Blankenship ve ark., 2005).

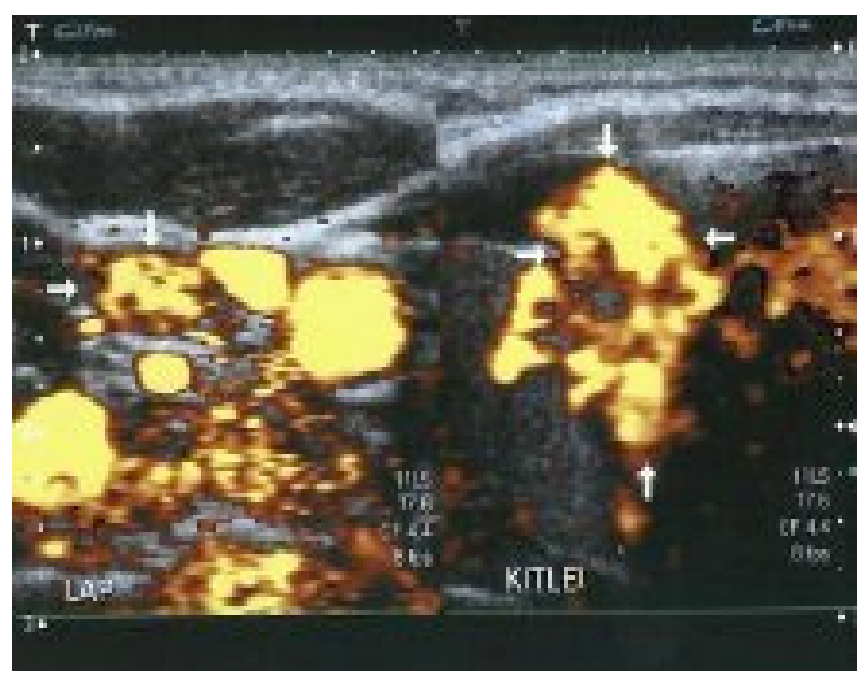

Şek. 4b. Aynı düzeyden elde edilen power Doppler ultrasonografide hem nodül, hem de lenf nodunda kanlanma (oklar)

Medüller tiroit kanserleri papiller kanserlere göre daha büyük boyutta, kistik komponent daha sık, solid komponenti homojendir.

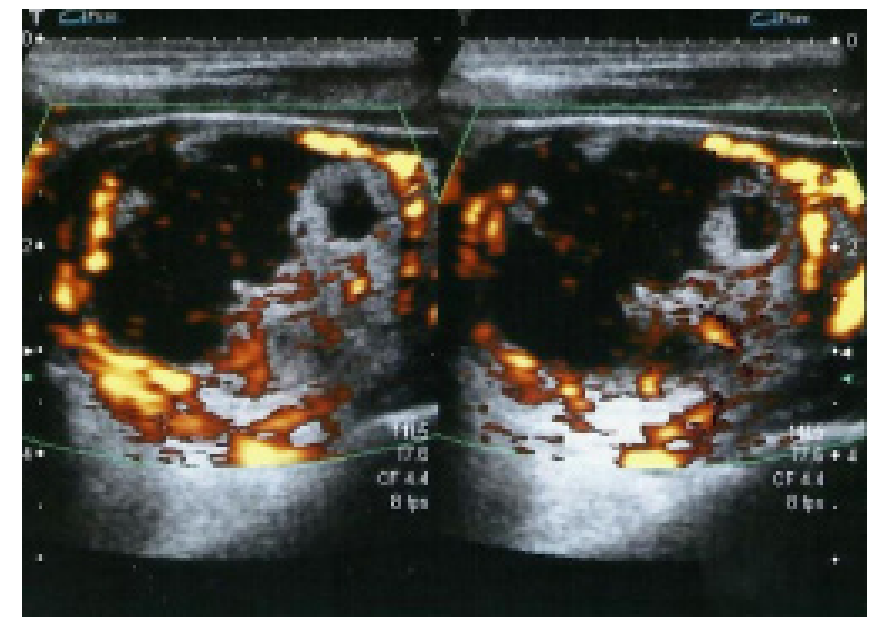

Şek. 5. Foliküler adenom, power Doppler ultrasonografide semisolid, çevresi ve solid alanları kanlanan nodül

Papiller karsinomlara göre daha s1k benign nodülle karışır. Medüller ve papiller kanserlerin çakışan US bulguları mevcuttur. Medüller kanserde \% 69,2 mikro, \% 30,8 oranında makrokalsifikasyon görülür (Şek. 6) (Lee ve ark., 2010). Anaplastik tiroit kanserleri ileri yaşta görülen, en agresif tümörlerden biridir. Hızlı büyür, tanı anında \% 40 metastaz vardır ve en sık akciğere metastaz yapar. Kalsfikasyon, nekroz içerebilen çevre dokulara invaze kitle görülür (Takashima ve ark., 1990).

Tiroidin epitelyum dişı tümörleri nadirdir. Bunlar teratom, hemanjiom, lenfoma, leyomyom, lipom ve Schwannom olup tüm tiroit tümörlerinin \% 1' den azıdır (Sugita ve ark., 1998).

\section{Tanıda İIAB'leri}

İ̇B tiroit nodüllerinin tanısında en etkin ve fiyat-efektif yöntemdir (Kim ve ark., 2008). İşlem için 22-27 G iğneler ve 2-20 ml arası enjektör kullanılır. Elde edilen materyal lama yayılarak bir bölümü havada kurutulur diğerleri ise hemen alkolle dolu kaba konarak fikse edilip patolojiye gönderilir. İşlem yeterlilik değerlendirmesi açısından sitopatolog eşliğinde yapılabilir. İİB geleneksel olarak tiroidte soliter nodül olduğunda kullanılmaktadır. Biyopsi bir cm'den büyük nodüller için düşünülse de bir cm'den küçük nodüllerde US bulgularında şüphe varsa gereklidir (Frates ve ark., 2005; AACE/ AME). Biyopsi öncesi US incelemesi yapılmalı ve tüm nodüller gözden geçirilmelidir. Dominant nodülden biyopsi yapmak kanserin gözden kaçmasına neden olabilir (Kim ve ark., 2008). Yeni literatürde soliter ve multinodüler hastalarda kanser riskinin benzer olduğunu bu nedenle multinodüler hastalarda IIIAB' lerin endike olduğu bildirilmektedir. US' de mikrokalsifikasyon, belirgin hipoekojenite, irregüler ya da mikrolobüle kontur, ön-arka çapın eninden fazla oluşu, nodül içi kanlanma, komşu organa invazyon, lenf noduna metastaz kanser için şüpheli bulgulardır (Kim ve ark., 2002). Tiroiditli hasta grubunda Haşimoto tiroiditinde nodüler lezyonlar görülebilir ve bu hastalarda lenfoma, kanser ayrımı için biyopsi yapılabilir (Pacini ve ark., 2001; Kwak ve ark., 2007). Kanser açısından riskli hasta grubunda risk taşımayanlara göre daha öncelikli olarak biyopsi endikasyonu vardır. Bu riskler tiroit kanseri aile öyküsüne sahip olmak, 30 yaş altı, 60 yaş üstü olmak, multiple endokrin neoplazi tip 2, boyuna radyasyon öyküsü ve erkek cinsiyettir (Titton ve ark., 2003). 


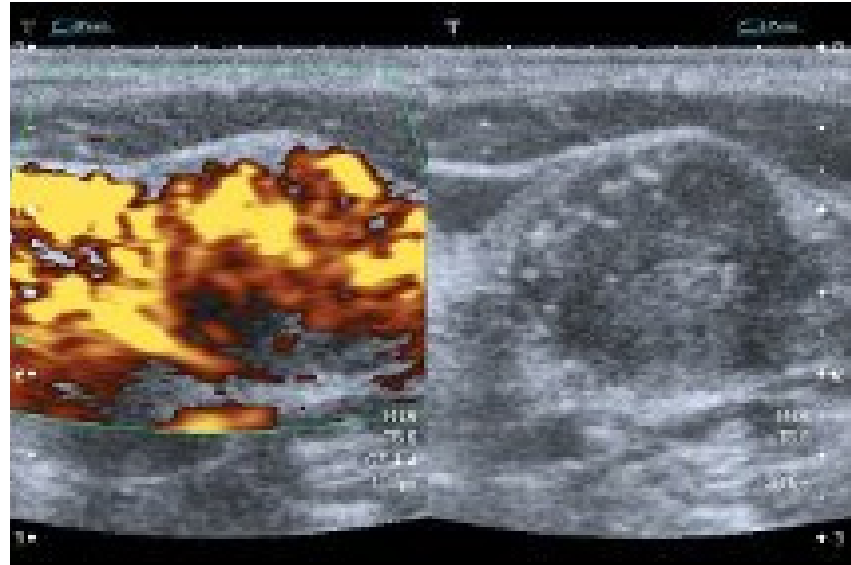

Şek. 6. Medullar kanser, primeri bilinmeyen kemik metastazı nedeniyle araştırılan hastada tiroidde mikro kalsifikasyon içeren nodül (sağda) ve power Doppler ultrasonografide belirgin kanlanma

\section{Malign nodüller için US bulguları}

Malign nodüller için US bulguları hipoekoik, mikrokalfikasyon, nodül çevresinde halo olmaması, düzensiz sınır, nodül içi kanlanma, eninden daha uzun ön-arka çaptır. Bu kriterlerin hiç biri spesifik değildir. Bu bulgulardan birden fazlasının bulunması özgüllüğü artırmaktadır. US nodülleri değerlendirmede önemli bir yöntem olmakla birlikte diğer önemli işlevi biyopsi yapılacak nodülün seçiminde kullanılmasıdır (Gharib ve ark., 2006; Pacini ve ark., 2006). US ayrıca servikal lenf nodu değerlendirmesinde de kullanılır. Servikal lenf nodu metastazında lenf nodu yuvarlaklaşabilir, solid ya da kistik olabilir ve ekojen hilusu kaybolur. Bazen de içinde noktasal kalsifikasyon saptanabilir. US tiroit hastalıklarında ilk kullanılan yöntemdir ancak nodüllerin malign benign ayrımında yardımcı değildir. Mikrokalsifikasyon kanser için en spesifik US bulgusudur. Lenfadenopati ve komşu organ invazyonu nadir ancak daha spesifik bir bulgudur. Say1, boyut ve büyüme aralığı nonspesifiktir. US' de şüpheli bulgular olması biyopsi için hasta ve nodül seçimine yardımcı olur (Hoang ve ark., 2007). US' de görülen nodüllerin özellikleri ve tanısal etkinlikleri aşağıda sunulmuştur.

\section{Kalsifikasyon}

Kalsifikasyon hem malign hem de benign nodüllerde görülür. Mikrokalsifikasyon, kaba kalsifikasyon veya kabuk şeklinde olabilir. Mikrokalsifikasyon tiroit kanserlerinde \% 29-59 oranında ve en sıklıkla da papiller kanserde görülür. Bunun dişında foliküler adenom, karsinom, anaplastik kanser, Haşimoto tiroiditinde de görülebilir (Taki ve ark., 2004). US' de akustik gölge vermeyen hiperekoik odaklar şeklinde görülür. Medüller kanserde kaba kalsifikasyon daha sık bir bulgudur. Periferal kalsifikasyon benign nodüllerde sıktır ancak malignde de olabilir (Propper ve ark., 1980).

\section{Lenf nodu metastazı}

Lenf nodu metastazında bulgular boyut artışı, yuvarlaklaşma, ekojen hilusun kaybı, düzensiz kenar, heterojen eko, kalsifikasyon, kistik alanlar, santral hiler kanlanma yerine tüm lenf nodunun kanlanmasıdır (Hoang ve ark., 2007).

\section{Halo}

Nodül çevresindeki halo fibröz dokudan oluşan bir psö- dokapsül, komprese tiroit parankimi ya da kronik enflamatuar infiltrasyon sonucu oluşabilir. Komplet, uniform halo benignite için hayli önemli bir bulgudur ve duyarlılı̆ $1 \% 95^{\prime}$ lerdedir. Ancak benign nodüllerin yarısından fazlasında halo yoktur ve papiller kanserler komplet ya da inkomplet haloya sahip olabilir (Hayashi ve ark., 1986; Lu ve ark., 1994).

\section{Nodül sınırları ve konturu}

Bir nodülün \% 50'den fazlasında sınırlar net seçilemiyorsa kötü sınırlı olarak değerlendirilir. Ayrıca nodülün konturu yumuşak ve yuvarlak ya da irregüler olarak tanımlanır. Kötü sınır ve irregüler kontur komşu dokuya malign infiltrasyon olarak düşünülür. Fakat bazı papiller kanserler US'de iyi s1nırlı görülebilir. Yine benign nodüller kötü sınırlı ve lobüle konturlu olabilir (Chan ve ark., 2003). Nodül şekli de tanıda kullanılan bir kriterdir. Nodülün ön- arka çapı enine çapından fazla ise malignite için \% 93 özgüllük bildirilmektedir (Kim ve ark., 2002).

\section{Vaskülarite}

Vaskülarite diğer bir değerlendirme kriteridir. Vasküler kan akımı renkli ya da power Doppler US ile değerlendirilebilir. En sık bulgu nodül içinde belirgin artmış ve çevreleyen parankime göre daha fazla düzeyde kanlanma olmasıdır. Bu bulgu \% 69-74 oranında görülür (Papini ve ark., 2002; Chan ve ark., 2003). Fakat malignite için spesifik değildir. Hipervasküler solid nodüllerin \% 50'den fazlası benigndir. Perinodüler kanlanma benign nodüllerde beklense de malign nodüllerde de görülebilir. Buna karşın tamamen avasküler nodül benignite için daha anlamlı bulunmuştur (Chan ve ark., 2003). Vasküleritenin değerlendirilmesi biyopsi açısından da önemlidir. Multinodüler olgularda biyopsi için nodül içi kanlanma olanlar seçilebilir. Bunun dışında içinde kanama ya da ekojenik debris olan nodüller de kanlanma olan solid alanlardan biyopsi yapılabilir (Hoang ve ark., 2007).

\section{Hipoekoik solid nodül}

Malign nodüller karsinom da olsa lenfoma da olsa parankime göre hipoekoik ve solid görülürler. Bu iki bulgu birlikte kullanıldığında duyarlılık yüksek (\% 87) ancak özgüllük düşüktür (\% 15,6-27) (Frates ve ark., 2005). Bu bulgu benign nodüllerin de \% 55' inde görülür. Ancak genel olarak belirgin hipoekojenite maligniteyi telkin eder (Taki ve ark., 2004).

\section{Nonspesifik US bulguları}

Nodül boyutu malignite tahmini ya da ekartasyonu için geçerli bir kriter değildir. Multinodüler olgularda yapılan en önemli yanlışlık en büyük nodülden biyopsi yapmaktır. Burada önerilen biyopsi için US değerlendirmesi ve buna göre nodülün seçilmesidir (Frates ve ark., 2005). Yapılan bir çalışmada 420 İİA yapılan bir seride eğer biyopsi için yalnızca bir cm üstü kriter alındığında seçilen 325 nodülde kanser tanıs1 \% 61 oranında olacağı saptanmıştır. Bunun yerine US de hipoekojenite, irregüler kontur, nodül içi kanlanma kriterleri kullanıldığında seçilen 125 nodülde kanser oranı \% 87 oranında saptanacaktı. Nodül çapı dört cm' yi geçerse malignite riski biraz daha artmaktadır. Ancak benign nodüller de büyük boyutta olabilir (Papini ve ark., 2002). Bununla birlikte 15 mm' den küçük papiller kanserli ve cerrahi olarak tedavi edilmiş olgularda 3,8 yıllık takipte ölen olgu bildirilmemiştir. Küçük lezyonlarda prognoz daha iyidir (Pellegriti ve ark., 2004). 
$\mathrm{Bu}$ nedenle malign nodüllerin erken saptanması önemlidir. Nodül sayısı tek olmasına rağmen kanser olabilirken multinodüler olgularda tümü benign olabilir. Yapılan bir çalışmada papiller kanser saptanan olgularda $\% 48$ oranında multinodüler görünüm mevcuttur (Jun ve ark., 2005). Bir başka seride 195 soliter nodülün 18 inde (\% 9,2) malignite, 207 multinodüler tiroidde ise 13 olguda (\% 6,3) malignite saptanmıştır (Papini ve ark., 2002). Foliküler kanser sıklıkla multinodüler zeminde görülür ve papiller kanserlerde \% 20 oranında multifokaldir (Middleton ve ark., 2004). Multinodüler olgularda bir ya da birkaç nodülden biyopsi yapılabilir. Biyopsi yapılacak nodül ya da nodüllerin seçiminde klinik bulgular, US' de şüpheli bulgu varlığı, hastadaki risk faktörleri dikkate alınır. Difüz büyümüş, benzer ve çok sayıda, US bulguları benign ve arada normal parankim olmayan olgularda biyopsiye muhtemelen gerek yoktur (Frates ve ark., 2005). Nodülün büyüme aralığıda malignite için geçerli bir kriter değildir. Klinik olarak hızlı büyüme anaplastik kanserde beklenen bulgudur ancak lenfoma, sarkom, yüksek gradeli karsinomlar da hızlı büyüyebilir (Hoang ve ark., 2007).

\section{Klinik yanılgıya neden olan durumlar}

Tiroide komşu anormal lenf nodları nodül ile karışabilir. Papiller kanserlerin kistik varyantı yine bir diğer yanılg1 nedenidir. Tiroit kanserlerinde \% 13-26 oranında kistik değişiklikler görülür. Papiller kanserlerin kistik ağırlıklı formunda görünüm hiperplastik nodül ile karışabilir. Ayrımda solid komponent de kanlanma, mikrokalsifikasyon ve solid komponentin kist içine protrüzyonu göz önüne alınır (Chan ve ark., 2003). Difüz infiltratif hipervasküler tümörde yanılg1 nedeni olabilir. Otoimmün Graves hastalığı, lenfositik tiroiditte bezde boyut artışı, azalmış ekojenite, heterojenite ve özellikle de Graves hastalığında daha belirgin olmak üzere hipervaskülarite görülür (Dahnert, 2003). Difüz infiltratif papiller kanser otoimmün tiroiditle karışabilir. Bez konturunda irregülarite, tiroidde nodüler büyüme, nodal metastaz US' de

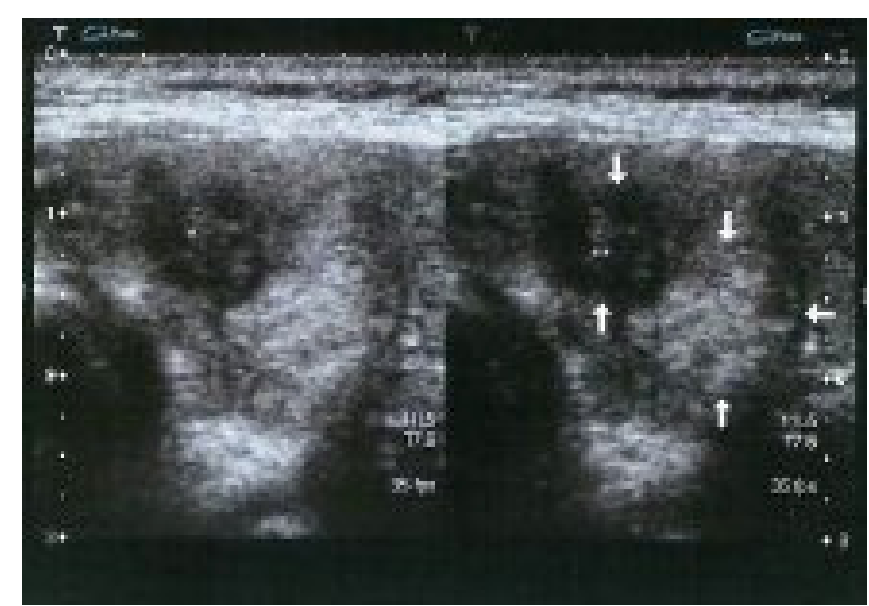

Şek. 7. Multinodüler guatrlı hastada hiperekojen iyi sınırlı nodül (benign nodül), bu nodülün medialinde kötü sınırlı hipoekoik nodül biopsi tanısı papiller kanser $(*)$

ayrıma yardımcıdır (Hoang ve ark., 2007).

Sonuç olarak US malign ya da malign potansiyeli olan nodülleri saptamada önemli bir yöntemdir. Benign ve malign nodüllerin bulgularında çakışma olmakla birlikte ayrıma yardımcı US bulguları mevcuttur. Mikrokalsifikasyon, lokal invazyon, lenf nodu metastazı, belirgin hipoekojenite, ön-arka çapın transversten fazla oluşu önemli bulgulardır. Bunun d1şında halonun olmayışı, kötü sınır, düzensiz kenar, solid görünüm ve nodül içi kanlanma daha az spesifik ancak yararlı bulgulardır (Şek. 7).

Lokal olarak tiroit dışına invazyon dışında yukarıdaki bulguların hiçbiri patognomonik değildir. Diğer yanılgı nedenleri küçük nodüllerin gözden kaçması, multipl nodüllerin çoğunlukla benign olduğunun düşünülmesi, kistik kanserlerin hiperplastik nodüllerle karışması ve Graves hastalığıdır (Hoang ve ark., 2007).

\section{KAYNAKLAR}

AACE/AME. 2006. Task force on thyroid nodules. American Association of Clinical Endocrinologists and Associazione Medici Endocrinologi medical guidelines for clinical practice for the diagnosis and management of thyroid nodules. Endocr. Pract. 12, 63-102.

Albrecht, T., Blomley, M., Bolondi, L., Claudon, M., Correas, J.M., Cosgrove, D., Greiner, L., Jäger, K., Jong, N.D., Leen, E., Lencioni, R., Lindsell, D., Martegani, A., Solbiati, L., Thorelius, L, Tranquart, F., Weskott, H.P., Whittingham, T. EFSUMB Study Group. 2004. Guidelines for the use of contrast agents in ultrasound. Ultraschall Med. 25, 249-256.

Blankenship, D.R., Chin, E., Terris, D.J., 2005. Contemporary management of thyroid cancer. Am. J. Otolaryng. 26, 249-260.

Bitterman, A., Uri, O., Levanon, A., Baron, E., Lefel, O., Cohen, O., 2006. Thyroid carcinoma presenting as a hot nodule. Otolaryng. Head Neck. 134, 888-889.

Chan, B.K., Desser, T.S., McDougall, I.R., Weigel, R.J., Jeffrey, R.B. Jr., 2003. Common and uncommon sonographic features of papillary thyroid carcinoma. J. Ultrasound Med. 22, 1083-1090.

Cochlin, D.L, Ganatra, R.H, Griffiths, D.F., 2002. Elastography in the detection of prostatic cancer. Clin. Radiol. 57, 1014-1020.1.

Cooper, D.S., Doherty, G.M., Haugen, B.R., Kloss, R.T., Lee, S.L., Mandel, S.J., Susan J.M., Mazzaferri, E.L., McIver, B., Pacini, F., Schlumberger, M., Sherman, S.I., Steward, D.L., Tuttle, M.R., 2009. Revised American Thyroid Association management guidelines for patients with thyroid nodules and differentiated thyroid cancer. Thyroid. 19, 1167-1214.

Cotran, R.S., Kumar, V., Robbins, S.L., 1994. Robbins pathologic basis of disease, 5th ed. Philadelphia: Saunders. 1121-1171.

Dahnert, W., 2003. Radiology review manual. 5th ed. Philadelphia, Pa: Lippincott Williams \& Wilkins, 394-396.

Deandrea, M., Mormile, A., Veglio, M., Motta, M., Pellerito, R., Gallone, G., Grassi, A., Torchio, B., Bradac, R., Garberoglio, R., Fonzo, D., 2002. Fine-needle aspiration biopsy of the thyroid: Comparison between thyroid palpation and ultrasonography. Endocr. Pract. 8, $282-286$.

Desser, T.S., Kamaya, A., 2008. Ultrasound of thyroid nodules. Neuroimag. Clin. N. Am. 18, 463-478.

Esen, G., 2006. Ultrasound of superficial lymph nodes. Eur. J. Radiol. 58, 345-359.

Frates, M.C., Benson, C.B., Charboneau, J.W., Cibas, E.S., Clark, O.H., Coleman, B.G., Cronan, J.J., Doubilet, P.M., Evans, D.B., Goellner, J.R., Hay, I.D., Hertzberg, B.S., Intenzo, C.M., Jeffrey, R.B., Langer, J.E., Larsen, P.R., Mandel, S.J., Middleton, W.D., Reading, C.C., Sherman, S.I., Tessler, F.N., Society of Radiologists in Ultrasound, 2005. Management of thyroid nodules detected at US: Society of Radiologists in Ultrasound consensus conference statement. Radiology. 237, 794-800.

Friedman, M., Shimaoka, K., Rao, U., Tsukada, Y., Gavigan, M., Tamura, K., 1981. Diagnosis of chronic lymphocytic thyroiditis (nodular pre- 
sentation) by needle aspiration. Acta Cytol. 25, 513-522.

Gharib, H., Papini, E., Valcavi, R., 2006. American Association of Clinical Endocrinologists and Associazione Medici Endocrinologi medical guidelines for clinical practice for the diagnosis and management of thyroid nodules. Endocr. Pract. 12, 63-102.

Gharib, H., 1997. Changing concepts in the diagnosis and management of thyroid nodules. Endocrin. Metab. Clin. 26, 777-800.

Gutekunst, R., Hafermann, W., Mansky, T., Scriba, P.C., 1989. Ultrasonography related to clinical and laboratory findings in lymphocytic thyroiditis. Acta Endocrinol. 121, 129-135.19.

Hodgson, K.J., Lazarus, J.H., Wheeler, M.H., 1988. Duplex scan derived thyroid blood flow in euthyroid and hyperthyroid patients. World J. Surg. 12, 470-475.

Hamming, J.F., Goslings, B.M., van Steenis, G.J., van Ravenswaay Claasen, H., Hermans, J., van de Velde, C.J., 1990. The value of fine-needle aspiration biopsy in patients with nodular thyroid disease divided into groups of suspicion of malignant neoplasms on clinical grounds. Arch. Intern. Med. 150, 113-116

Hayashi, N., Tamaki, N., Yamamoto, K., Senda, M., Yonekura, Y., Misaki, T., Iida, Y., Kasag1, K., Endo, K., Konishi, J., 1986. Realtime ultrasonography of thyroid nodules. Acta. Radiol. Diagn. 27, 403-408.

Hedinger, C., Williams, E.D., Sobin, L.H., 1989. The WHO histological classification of thyroid tumors: A commentary on the second edition. Cancer. 63, 908-911.

Hoang, J.K., Lee, W.K., Lee, M., Johnson, D., Farrell, S., 2007. US features of thyroid malignancy: Pearls and pitfalls. RadioGraphics 27, 847865.

Itoh A, Ueno E, Tohno E, Kamma, H., Takahashi, H., Shiina, T., Yamakawa, M., Matsumura, T., 2006. Breast disease: Clinical application of US elastography for diagnosis. Radiology. 239, 341-350.

Ito, Y., Tomoda, C., Uruno, T., Takamura, Y., Miya, A., Kobayashi, K., Matsuzuka, F., Kuma, K., Miyauchi, A., 2004. Preoperative ultrasonographic examination for lymph node metastasis: Usefulness when designing lymph node dissection for papillary microcarcinoma of the thyroid. World J. Surg. 28, 498-501.

Jun, P., Chow, L.C., Jeffrey, R.B., 2005. The sonographic features of papillary thyroid carcinomas: pictorial essay. Ultrasound Q. 21 , $39-45$.

Kim, E.K., Park, C.S., Chung, W.Y.,Oh, K.K., Kim, D.I., Lee, J.T., Yoo, H.S., 2002. New sonographic criteria for recommending fine-needle aspiration biopsy of nonpalpable solid nodules of the thyroid. AJR 178,687-691.

Kim, M.J., Kim, E.K., Park, C.S., Kim, B.M., Kim, J.S., Youk, J.H., Park, S.H., 2008. US-guided fine-needle aspiration of thyroid nodules: Indications, techniques, results. RadioGraphics. 28, 1869-1889.

Koike, E., Noguchi, S., Yamashita, H., et al. 2001. Ultrasonographic characteristics of thyroid nodules: Prediction of malignancy. Arch. Surg. 136, 334-337.

Kwak, J.Y., Kim, E.K., Ko, K.H., Yang, W.I., Kim, M.J., Son, E.J., Oh, K.K., Kim, K.W., 2007. Primary thyroid lymphoma: Role of ultrasoundguided needle biopsy. J. Ultrasound Med. 26, 1761-1765.

Layfield, L.J., Cibas, E.S., Gharib, H., Mandel, S.J., 2009. Thyroid aspiration cytology: Current status. Cancer J. Clin. 59, 99-110.

Lee, S., Shin, J.H., Han, B.K., Ko, E.Y., 2010. Medullary thyroid carcinoma: Comparison with papillary thyroid carcinoma and application of current sonographic criteria. A.J.R. 194,1090-1094.

Lu, C., Chang, T.C., Hsiao, Y.L., Kuo, M.S., 1994. Ultrasonographic findings of papillary thyroid carcinoma and their relation to pathologic changes. J. Formos Med. Assoc. 93, 933-938.

Lyshchik, A., Higashi, T., Asato, R., Tanaka, S., Ito, J., Mai, J.J., Pellot-Barakat, C., Insana, M.F., Brill, A.B., Saga, T., Hiraoka, M., Togashi, K., 2005. Thyroid gland tumor diagnosis at US elastography. Radiology. 237, 202-211

Marcocci, C., Vitti, P., Cetani, F., Catalano, F., Concetti, R., Pinchera, A., 1991. Thyroid ultrasonography helps to identify patients with diffuse lymphocytic thyroiditis who are prone to develop hypothyroidism. J. Clin. Endocr. Metab.72, 209-213.

Mazzaferri, E.L., 1993. Management of a solitary thyroid nodule. New Engl. J. Med. 328, 553-559.

Middleton, W.D., Kurtz, A.B., Hertzberg, B.S., 2004. Ultrasound: The requisites. 2nd ed. St Louis, Mo: Mosby, 244-252.

Miltenburg, D.M., Prost, H.M., Graviss, E.A., Arem, R., 2000. Role of frozen section, gender, age, and tumor size in the differentiation of follicular adenoma from carcinoma: A meta-analysis. Surgery. 128, 1075-1081.

Moon, W.J., Jung, S.L., Lee, J.H., Na, D.G., Baek, J-H., Lee, Y.H., Kim, J., Kim, H.S., Byun, J.S., Lee, D.H., For the Thyroid Study Group, Korean Society of Neuro- and Head and Neck Radiology, 2008. Benign and malignant thyroid nodules: US differentiation-multicenter retrospective study. Radiology. 247, 762-770.

Mulder, J.E., 1998. Thyroid disease in women. Med. Clin. N. Am. 82,103-125.

National Comprehensive Cancer Network Website. Thyroid Carcinoma. ww.nccn.org/professionals/physician_gls/f_guidelines.asp. Accessed June 25, 2010-30.

National Cancer Institute Website. NCI Cancer Bulletin for February 19, 2008.www.cancer.gov/ncicancerbulletin/NCI_Cancer_Bulletin_021908/ page3. Accessed June 25, 2010.

Ophir, J., Céspedes, I., Ponnekanti, H., Yazdi, Y., Li, X., 1991. Elastography: A quantitative method for imaging the elasticity of biological tissues. Ultrasonic Imaging. 13, 111-134.

Pacini, F., Schlumberger, M., Dralle, H., Elisei, R., Smit, J.W., Wiersinga, W., European Thyroid Cancer Taskforce. 2006. European Thyroid Cancer Taskforce, European consensus for the management of patients with differentiated thyroid carcinoma of the follicular epithelium. Eur. J. Endocrinol. 154, 787-803.

Pacini, F., Elisei, R., Capezzone, M., Miccoli, P., Molinaro, E., Basolo, F., Agate, L., Bottici, V., Raffaelli, M., Pinchera, A., 2001. Contralateral papillary thyroid cancer is frequent at completion thyroidectomy with no difference in low- and high-risk patients. Thyroid.11, 877-881.

Papini, E., Guglielmi, R., Bianchini, A., Crescenzi, A., Taccogna, S., Nardi, F., Panunzi, C., Rinaldi, R., Toscano, V., Pacella, C.M.., 2002. Risk of malignancy in nonpalpable thyroid nodules: Predictive value of ultrasound and color-Doppler features. J. Clin. Endocr. Metab. 87, 19411946.

Pellegriti, G., Scollo, C., Lumera, G., Regalbuto, C., Vigneri, R., Belfiore, A., 2004. Clinical behavior and outcome of papillary thyroid cancers smaller than $1.5 \mathrm{~cm}$ in diameter: Study of 299 cases. J. Clin. Endocr. Metab. 89, 3713-3720.

Propper, R.A., Skolnick, M.L., Weinstein, B.J., Dekker, A., 1980. The nonspecificity of the thyroid halo sign. J. Clin. Ultrasound. 8, $129-132$.

Rago, T., Di Coscio, G., Basolo, F., Scutari, M., Elisei, R., Berti, P., Miccoli, P., Romani, R., Faviana, P., Pinchera, A., Vitti, P., 2007. Combined clinical, thyroid ultrasound and cytological features help to predict thyroid malignancy in follicular and Hupsilonrthle cell thyroid lesions: Results from a series of 505 consecutive patients. Clin. Endocrinol. 66, 13-20. 
Rago, T., Vitti, P., 2008. Role of thyroid ultrasound in the diagnostic evaluation of thyroid nodules. Best Pract. Res. Cl. En. 22, 913-928.

Sameer, A., Karen, M.H., Brooke, J.R., Sheth, S., Fishman, E.K., 2010. Incidental thyroid nodules on chest CT: Review of the literature and management suggestions. A.J.R; 195, 1066-1071.

Schueller-Weidekamm, C., Kaserer, K., Schueller, G., Scheuba, C., Ringl, H., Weber, M., Czerny, C., Herneth, A.M., 2009. Can quantitative diffusion-weighted MR imaging differentiate benign and malignant cold thyroid nodules? Initial results in 25 patients. Am. J. Neuroradiol. $30,417-422$

Shirakawa, T., Miyamoto, Y., Yamagishi, J., Fukuda, K., Tada, S., 2001. Color/power Doppler sonographic differential diagnosis of superficial lymphadenopathy: Metastasis, malignant lymphoma, and benign process. J. Ultras. Med. 20, 525-532.

Sillery, J.C., Carl, C., Charboneau, J.W., Henrichsen, T.L., Hay, I.D., Mandrekar, J.N., 2010. Thyroid follicular carcinoma: Sonographic features of 50 Cases. A.J.R. 194, 44-54.

Sippel, R.S., Elaraj, D.M., Khanafshar, E., Kebebew, E., Duh, Q.Y., Clark, O.H., 2007. Does the presence of additional thyroid nodules on ultrasound alter the risk of malignancy in patients with a follicular neoplasm of the thyroid? Surgery. 142, 851-857

Stolf, B.S., Santos, M.M., Simao, D.F., Diaz, J.P., Cristo, E.B., Hirata, R. Jr., Curado, M.P., Neves, E.J., Kowalski, L.P., Carvalho, A.F., 2006. Class distinction between follicular adenomas and follicular carcinomas of the thyroid gland on the basis of their signature expression. Cancer. 106,1891-1900.

Sugita, R., Nomura, T., Yuda, F., 1998. Primary schwannoma of the thyroid gland: CT findings. A.J.R. 171, 528-529.

Takashima, S., Morimoto, S., lkezo, J., Takai, S., Kobayashi, T., Koyama, H., Nishiyama, K., Kozuka, T., 1990. CT evaluation of anaplastic thyroid carcinoma. A.J.R. 154,1079-185.

Taki, S., Terahata, S., Yamashita, R., Kinuya, K., Kakuda K., Nobata, K., Kodama, Y., Yamamoto, I., 2004. Thyroid calcifications: Sonographic patterns and incidence of cancer. Clin. Imag. 28, 368-371.

Tessler, F.N., Tublin, M.E., 1999. Thyroid sonography: Current applications and future directions. A.J.R.173,437-443.

Titton, R.L., Gervais, D.A., Boland, G.W., Maher, M.M., Mueller, P.R., 2003. Sonography and sonographically guided fine-needle aspiration biopsy of the thyroid gland: Indications and techniques, pearls and pitfalls. A.J.R. 181, 267-271.

Varverakis, E., Neonakis, E., 2002. Contribution of high-resolution ultrasonography in the differential diagnosis of benign from malignant thyroid nodules. Hormones. 1, 51-56.

Vi1, P., Rago, T., Mancusi, F., Pallini, S., Tonacchera, M., Santini, F., Chiovato, L., Marcocci, C., Pinchera, A., 1992. Thyroid hypoechogenic pattern at ultrasonography as a tool for predicting recurrence ofhyperthyroidism after modical treatment in patients with Graves' disease. Acta Endocrinol.126, 128-131. 